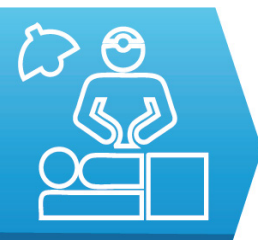

SURGERY

\title{
Fistulectomy and incontinence: do we really need to worry?
}

Jahangeer Maqbool, Asif Mehraj, Zamir A Shah, Gowhar Aziz, Rauf A Wani, Fazl Q Parray, Nisar A Chowdri
Department of General Surgery (Colorectal Division), Sher I Kashmir Institute of Medical Sciences, Srinagar, India
DOI: $10.15386 / \mathrm{mpr}-2045$

Manuscript received: 16.01 .2021

Received in revised form: 01.03.2021

Accepted: 24.03.2021

Address for correspondence:

asifdr80@yahoo.co.in

This work is licensed under a Creative Commons Attribution-NonCommercialNoDerivatives 4.0 International License

\begin{abstract}
Background. Anal fistula is often considered to be a dilemma because of the need to maintain a fine balance between postoperative incontinence and recurrence. We tried to find whether apprehension of causing incontinence should stop us from performing fistulectomy. The aim of this study was to determine whether fistulectomy was associated with increased rate of fecal incontinence and recurrence, compared to other procedures used for the treatment of anal fistula.

Methods. It was a prospective, single center, observational study. All patients with anal fistula operated at a tertiary care teaching institute over a period of two years were included in the study. Recurrence rates and fecal incontinence were compared between patients subjected to fistulectomy and other procedures for treatment of fistula in ano.

Results. A total of 124 patients with anal fistula were included. $92.8 \%$ patients were $\leq 60$ years of age with high male preponderance $(89.5 \%)$. Perineal discharge was the commonest complaint $(95.96 \%)$. Intersphincteric $(47.58 \%)$ followed by transphincteric fistulas $(45.16 \%)$ accounted for the majority of fistulas. Fistulectomy was the most common procedure, performed in $90(72.58 \%)$ patients. Incontinence occurred in $8 / 90(8.88 \%)$ from the fistulectomy group and $2 / 34(5.9 \%)$ patients in other surgery group, $\mathrm{p}=0.726$. Recurrence occurred in $8 / 90(8.88 \%)$ from the fistulectomy group and $8 / 34$ (23.5\%) patients from other surgery group, $\mathrm{p}=0.038$. Overall rates of incontinence and recurrence were $8.1 \%$ and $12.9 \%$ respectively.
\end{abstract}

Conclusion. Fistulectomy, as compared to other procedures, results in less chances of recurrence without compromising continence.

Keywords: fistula in ano, fistulectomy, incontinence, recurrence

\section{Introduction}

The prevalence of nonspecific anal fistula has been estimated to be 8.6-10/100,000, with a male to female ratio of 1.8:1 [1,2]. Anal fistula has been known since ancient times. It is known since the times of Hippocrates who described it and proposed the use of seton as a treatment option [3].

In around $90 \%$ of case, anal fistulas are caused as a result of infection of Herman and Defosses anal glands, also called cryptoglandular hypothesis of Eisenhammer. Other rare causes of anal fistula include tuberculosis, inflammatory bowel diseases especially
Crohn's disease, lymphogranuloma inguinale, etc. External trauma or iatrogenic injury can also lead to formation of perianal fistulas. A fistula may also develop in chronic anal fissure, an entity called fissure fistula complex. A colloid carcinoma of the rectum can present as perianal fistula [4].

Perianal fistula is not only associated with clinical diversity but being in proximity to anal sphincters it poses the challenge of incontinence if radical procedure is undertaken, and recurrence if under treated.

Various treatment options for anal fistula have been proposed from 
time to time with varying success rates, such as mucosal advancement flaps (59-78\%) [5], fibrin glue injection (38$41 \%$ ) [6], anal fistula plugs (54-85\%) [7-9], ligation of intersphincteric fistula tract (LIFT) (57-94\%) [10], video assisted anal fistula treatment (VAAFT) (66.7- 87.5\%) $[11,12]$, laser closure of fistula tract (FiLAC) $(67.3-69.7 \%)$ [13], Fistulectomy/ Fistulotomy (93-100\%) [14-16].

Surgeons try to be conservative in treating fistula to avoid incontinence at the cost of high recurrence rate. We performed a prospective study with the aim to determine whether fistulectomy was associated with increased rate of fecal incontinence and recurrence as compared to other procedures for the treatment of fistula in ano.

\section{Patients and methods}

This was a single center, prospective, observational study, conducted at a tertiary level teaching hospital. All the patients who were operated for anal fistula from July 2017 to April 2019 were enrolled in the study. Patients were followed for a minimum of 18 months to check for fecal incontinence and recurrence.

All the patients were evaluated with detailed history, physical examination, including digital rectal examination and proctoscopy. MR fistulography was done selectively for patients with complex fistulas only (Figure 1). A detailed questionnaire was filled which included parameters like age, sex, weight, height, BMI, clinical presentation, number and location of external and internal openings, characteristics of the fistulous tract, course and type of fistula based on Parks, classification and any previous surgical interventions. All the procedures were done under spinal anesthesia in lithotomy position and the type of procedure was decided by the operating surgeon after examining the patient under anesthesia. For fistulectomy with coring out technique (Figure 2), a mixture of methylene blue and hydrogen peroxide was injected into the external opening. Besides helping identify the internal opening in a good number of cases, this also delineates the track, so that the dissection is limited around the fistulous track only. In case the track was not delineated, continuous palpation of the indurated tract was done, so as to limit our dissection just around the fistula. Once the intersphincteric portion was reached, the track was pulled to help in identifying the internal opening, if it had not been previously identified using the dye. It is of utmost importance to remove the whole of anal gland complex, which can be identified as a yellowish structure in the submucosal region. In the majority of cases, the mucosal defect was closed with an absorbable suture, so as to prevent fecal contamination of the wound. The resected tract and granulation tissue was sent for histopathological examination for all the patients. Patients were discharged within few days depending upon the type of wound and their attendants were taught how to dress and clean the wound at home. Postoperative follow up was done at 2, 4, 6 weeks and 6, 12 and 18 months to assess the outcome of various surgical techniques in terms of wound healing, scaring, infection rates, incontinence, recurrence, etc. For comparison of results, patients were divided into two groups, those subjected to fistulectomy in group 1 and patients subjected to other procedures to group 2. Cleveland clinic incontinence score (CCIS) was used to assess the continence level at 6,12 and 18 month follow up and compared with preoperative values. A score of 0-5, 6-15 and 16-20 were considered as mild, moderate and severe incontinence respectively. Recurrence was defined by reemergence of preoperative symptoms and confirmation by MR fistulogram.

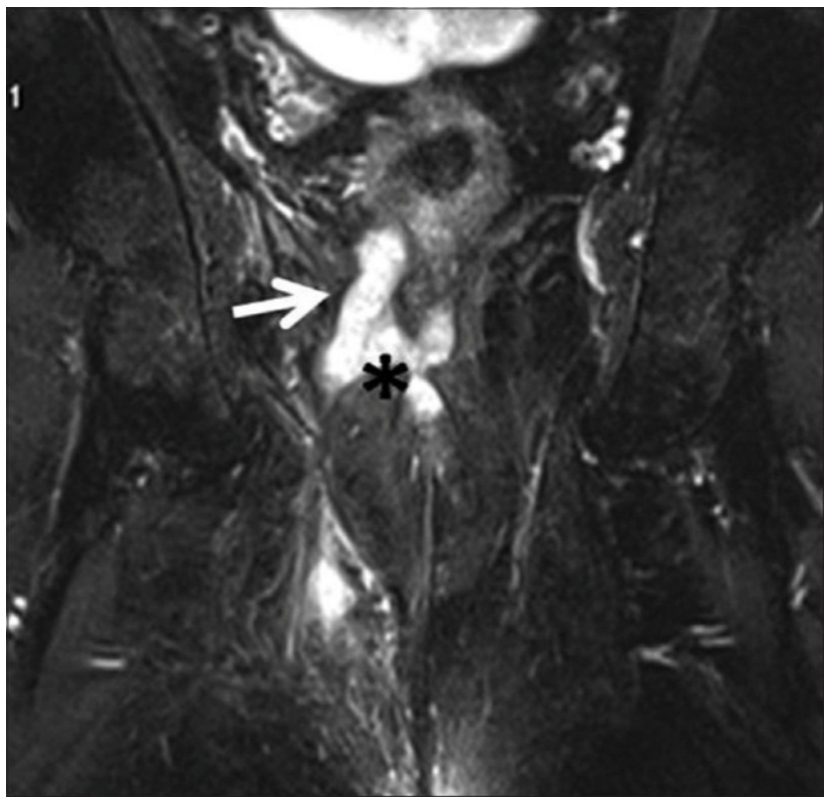

Figure 1. Showing anal fistula with abscess marked by asterisk and intersphincteric tract marked by arrow (MRI grade II).

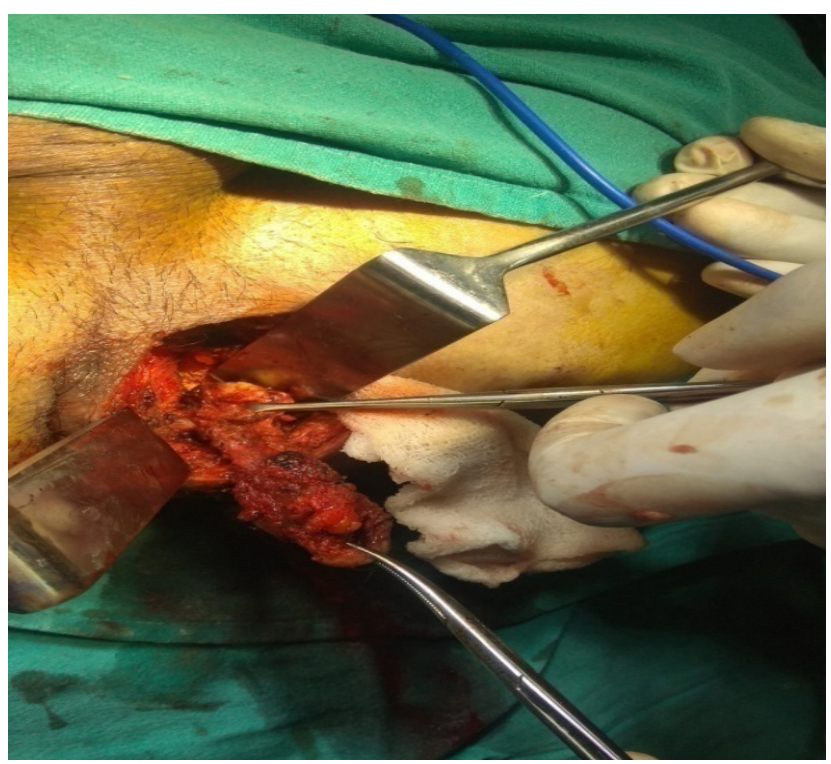

Figure 2. Showing fistulous tract being excised. 


\section{Statistical Analysis}

Data were collected on MS Excel sheet. Data on categorical variables were presented as $n$ ( $\%$ of cases). Statistical significance of the difference of categorical variables was tested using the Fischer exact test. $P$ value $<0.05$ was considered to be statistically significant. Data was analyzed using the Statistical Package for Social Sciences (SPSS) for Windows, Version 20.0, (IBM Corporation, Armonk, NY, USA) for MS Windows. The data were finally collected and analyzed using appropriate statistical tests and final inferences were drawn.

\section{Results}

The total number of patients in our study was 124 . Majority of the patients were male, $111(89.5 \%)$, with a male to female ratio of 8.5:1. Maximum numbers of patients $(64.6 \%)$ were in the age group of 25 to 45 years, with a mean age of 38.2 years. Perineal discharge $(95.96 \%)$ was the commonest complaint followed by perianal swelling and pain. Fever, perineal itching and bleeding PR were complained by a smaller subset of patients. Past history of peri anal abscess drainage was given by 65 (52.4\%) patients. Intersphincteric (47.58\%) and Transphincteric $(45.16 \%)$ fistulas were the predominant types, Suprasphincteric (4\%) and Extrasphincteric (3.22\%) types represented a minority of the cases. Fistulectomy was the commonest procedure performed on $90(72.5 \%)$ patients. Among these 90 patients, 3 patients underwent fistulectomy with primary sphincter repair. In others fistulectomy was performed using coring out technique. Other procedures included fistulotomy (17, 13.8\%), Fistula Laser Closure (FiLaC) (4, 3.2\%), LIFT (8, 6.5\%), mucosal advancement flap $(2,1.6 \%)$, seton placement $(2$, $1.6 \%$ ) and Wide Local Excision of carcinoma in fistulous tract $(1,0.8 \%)$. Out of a total number of 124 patients, 120 (96.8\%) had nonspecific chronic inflammation, 2 (1.6\%) had tuberculous pathology, $1(0.8 \%)$ had Crohn's disease and $1(0.8 \%)$ patient had mucinous adenocarcinoma. Post operative wound infection was observed in 23 (18.54\%) patients, urinary retention in $6(4.83 \%)$ patients and postoperative headache (due to spinal anesthesia) in 2 patients (1.6\%). Follow up ranged from 18 to 39 months. Cleveland Clinic Incontinence score (CCIS) was used to assess incontinence level (Table I). Incontinence at 18 months (both mild and moderate together) was observed in a total of $10 / 124(8.1 \%)$ patients. There was no statistically significant difference between incontinence rate among fistulectomy group and other surgery group $(8.88 \%$ vs. $5.9 \%, \mathrm{p}=0.63)$. Overall, $16 / 124$ (12.9\%) patients developed recurrence. Recurrence rate were significantly less in fistulectomy group as compared to other surgery group ( $8.88 \%$ vs. $23.5 \%, \mathrm{p}=0.038)$. Table II summarizes the clinical features of patients who developed recurrence. Table III compares the outcomes between fistulectomy and other surgeries for fistula in ano. No mortality was recorded in this study.

Table I. Patients with incontinence.

\begin{tabular}{l|l|c|c|c|c} 
& \multirow{2}{*}{ S. No } & Surgery & \multicolumn{5}{c}{ CCIS / Wexner score } \\
\cline { 3 - 6 } & & Pre Op & $\mathbf{6}$ weeks & $\mathbf{3}$ months & $\mathbf{1 2}$ months \\
\hline 1. & Fistulectomy & 0 & 4 & 2 & 2 \\
2. & Fistulectomy with sphincter reconstruction & 0 & 6 & 3 & 2 \\
3. & FILAC & 0 & 3 & 2 & 1 \\
4. & Fistulectomy & 0 & 3 & 1 & 1 \\
5. & Fistulectomy & 1 & 16 & 9 & 7 \\
6. & Fistulectomy & 0 & 4 & 3 & 2 \\
7. & Fistulectomy & 0 & 8 & 4 & 3 \\
8. & Fistulectomy with sphincter reconstruction & 0 & 12 & 5 & 3 \\
9. & Fistulectomy & 0 & 8 & 5 & 2 \\
10. & Fistulotomy & 0 & 3 & 1 & 1
\end{tabular}

CCIS $=$ Cleveland clinic incontinence score. 
Table II. Characteristics of patients with recurrence.

\begin{tabular}{|c|c|c|c|c|c|c|}
\hline S no & $\begin{array}{l}\text { Type of } \\
\text { fistula }\end{array}$ & $\begin{array}{l}\text { Previous } \\
\text { surgery }\end{array}$ & $\begin{array}{l}\text { Number } \\
\text { of } \mathbf{E O}\end{array}$ & $\begin{array}{l}\text { Horse shoe } \\
\text { tract }\end{array}$ & Surgical procedure & Histology \\
\hline 1. & SSF & YES & 1 & $\mathrm{NO}$ & Fistulectomy with curettage & Non specific chronic inflammation \\
\hline 2. & TSF & NO & 3 & YES & Fistulectomy & Tuberculosis \\
\hline 3. & TSF & YES & 2 & YES & FILAC & Non specific chronic inflammation \\
\hline 4. & TSF & NO & 1 & NO & FILAC & Non specific chronic inflammation \\
\hline 5. & ESF & NO & 1 & NO & Fistulectomy & Non specific chronic inflammation \\
\hline 6. & ISF & NO & 1 & NO & Fistulotomy & Non specific chronic inflammation \\
\hline 7. & ESF & NO & 1 & NO & Fistulectomy & Non specific chronic inflammation \\
\hline 8. & SSF & YES & 1 & NO & Fistulectomy with curettage & Non specific chronic inflammation \\
\hline 9. & ISF & YES & 1 & NO & Fistulotomy & Non specific chronic inflammation \\
\hline 10. & TSF & YES & 3 & YES & Fistulectomy & Tuberculosis \\
\hline 11. & TSF & NO & 3 & YES & Fistulectomy & Adenocarcinoma \\
\hline 12. & TSF & NO & 1 & NO & Fistulotomy & Non specific chronic inflammation \\
\hline 13. & ISF & YES & 1 & NO & Fistulotomy & Non specific chronic inflammation \\
\hline 14. & TSF & NO & 2 & NO & Fistulectomy & Crohn's \\
\hline 15. & ISF & NO & 1 & NO & FILAC & Non specific chronic inflammation \\
\hline 16. & TSF & NO & 1 & NO & LIFT & Non specific chronic inflammation \\
\hline
\end{tabular}

Table III. Comparison of outcomes between fistulectomy and other surgeries.

\begin{tabular}{ll|c|c|c|c} 
Outcome & & Total (124) & Fistulectomy (90) & Other group (34) & P value \\
Recurrence & Yes & $16(12.9)$ & $8(8.88)$ & $8(23.5)$ & 0.038 \\
& No & $108(87.1)$ & $82(91.22)$ & $26(76.5)$ & \\
Incontinence & Yes & $10(8.1)$ & $8(8.88)$ & $2(5.9)$ & 0.63
\end{tabular}

\section{Discussion}

Fistulectomy was the most common type of surgery performed in our study. A total of $90(72.58 \%)$ patients underwent this operation. We routinely perform fistulectomy with coring out technique, as it seems to be an ideal option with less damage to sphincters but at the same time more effective in eradicating the disease in both simple and complex variety of fistulas. Fistulectomy by coring out technique achieves both objectives of avoiding damage to sphincters and at the same time eradicates the pathology effectively. In case fistula is so complex that the division of sphincter is inevitable for achieving complete excision of the diseased tissue, primary sphincter reconstruction is done to avoid postoperative incontinence. Other procedures like fistulotomy, LIFT and FILac were used for very less number of patients because we are satisfied with the results of more radical procedures. Though the newer techniques are sphincter saving but the success rates are not acceptable.
The overall incontinence rate following surgery for anal fistula may be as high as $73.7 \%$ [17]. Following fistulectomy procedure, the incontinence can range from 11.5 to $20 \%$ [18]. In our study, overall incontinence rate was $8.1 \%$ at 18 month follow up using CCIS. Fistulectomy was associated with an overall incontinence rate of $8.88 \%$ ( 8 out of 90 patients). The severity of incontinence decreased with time. Among the 8 patients that developed incontinence following fistulectomy, 7 had mild form of incontinence with CCIS $\leq 5$. Only 1 patient developed moderate incontinence with CCIS of 7 at 12 month follow up (Table I). In the other surgery group 2 $(5.9 \%)$ patients developed incontinence which was mild in severity. All patients were managed conservatively by means of bulking agents for stool and increasing dietary fiber, followed by training of the pelvic floor muscles by regular exercises. There was no worsening of quality of life related to fecal incontinence in any of our patients. The rate of incontinence was similarly reported by Kanchwala 
et al. [19] who observed incontinence rate of $8.8 \%$ and Bokhari et al. [20], who observed slightly more rate of incontinence at around $13 \%$ in their patients at Cleveland clinic, USA.

Recurrence following fistula surgery is one more important outcome to look for. A recent meta-analysis showed recurrence rates after surgery for anal fistula ranging from $2.5 \%$ to $57.1 \%$ [21]. In the same metaanalysis, the most important risk factors for recurrence were revealed to be high transphincteric fistula, nondetected internal opening, treating the fistula only with seton drain, the presence of a horseshoe-formed abscess, more than one fistula tracts and prior anal surgery. In our study, overall recurrence occurred in 14 patients (11.29\%). The results are consistent with the observations made by Abraham Jebakumar et al. [22] who reported a recurrence rate of $13 \% .8$ out of $90(8.88 \%)$ patients who underwent fistulectomy developed recurrence, thereby giving a success rate of $91.12 \%$. However, it is interesting to note that all these patients had complex fistulas (Table II). The risk of recurrence was directly related to the complexity of fistula, with $50 \%$ of the extrasphincteric and $40 \%$ of suprasphincteric fistulae developing recurrence. This is because of left over portion of unhealthy tract/granulation tissue and improper postoperative wound management leading to premature wound closure. However, it is difficult to comment on this observation as number of complex fistulas was less in this study. Such patients need longer follow up to be able to comment on actual figures for recurrence and incontinence. According to existing data, the true recurrence rate for every surgical technique becomes more evident after longer follow up periods. In comparison to fistulectomy, other procedures had a significantly higher rate of recurrence $(23.5 \%, \mathrm{p}=0.038)$.

\section{Conclusion}

Fistula surgery continues to pose challenges to surgeons all around the world. There is no single operative procedure which can be set as a gold standard. The management issues usually need to maintain a good balance between recurrence and incontinence. Both these outcomes vary from procedure to procedure and center to center. If performed correctly, fistulectomy using coring out technique is not associated with significant rates of incontinence and also results in low recurrence rate as compared to other surgical options for the treatment of fistula in ano.

\section{References}

1. Sheikh P, Bajaj P. Perianal Sepsis and Fistula. In: Chowdri N., Parray F. (eds). Benign Anorectal Disorders. Springer, New Delhi; 2016: pp. 47-69.
2. Deeba S, Aziz O, Sains PS, Darzi A. Fistula-in-ano: advances in treatment. Am J Surg. 2008;196:95-99.

3. Babu AK, Naik MB, Babu MR, Madhulikia M. Seton - as a gold standard treatment for high fistula in ano, Journal of Evidence Based Medicine and Healthcare 2015;2:16871693.

4. Adams D, Kovalcik PJ. Fistula in ano. Surg Gynecol Obstet. 1981;153:731-732.

5. Mizrahi N, Wexner SD, Zmora O, Da Silva G, Efron J, Weiss EG, et al. Endorectal advancement flap: are there predictors of failure? Dis Colon Rectum. 2002;45:1616-1621.

6. Yeung JM, Simpson JA, Tang SW, Armitage NC, MaxwellArmstrong C. Fibrin glue for the treatment of fistulae in ano--a method worth sticking to? Colorectal Dis. 2010;12:363-366.

7. Champagne BJ, O'Connor LM, Ferguson M, Orangio GR, Schertzer ME, Armstrong DN. Efficacy of anal fistula plug in closure of cryptoglandular fistulas: long-term follow-up. Dis Colon Rectum. 2006;49:1817-1821.

8. O'Riordan JM, Datta I, Johnston C, Baxter NN. A systematic review of the anal fistula plug for patients with Crohn's and non-Crohn's related fistula-in-ano. Dis Colon Rectum. 2012;55:351-358.

9. Schwandner O, Stadler F, Dietl O, Wirsching RP, Fuerst A. Initial experience on efficacy in closure of cryptoglandular and Crohn's transsphincteric fistulas by the use of the anal fistula plug. Int J Colorectal Dis. 2008; 23:319-324.

10. Kontovounisios C, Tekkis P, Tan E, Rasheed S, Darzi A, Wexner SD. Adoption and success rates of perineal procedures for fistula-in-ano: a systematic review. Colorectal Dis. 2016;18:441-458.

11. Meinero P, Mori L, Gasloli G. Video-assisted anal fistula treatment: a new concept of treating anal fistulas. Dis Colon Rectum. 2014;57:354-359.

12. Mendes CR, Ferreira LS, Sapucaia RA, Lima MA, Araujo SE. Video-assisted anal fistula treatment: technical considerations and preliminary results of the first Brazilian experience. Arq Bras Cir Dig. 2014;27:77-81.

13. Elfeki H, Shalaby M, Emile SH, Sakr A, Mikael M, Lundby L. A systematic review and meta-analysis of the safety and efficacy of fistula laser closure. Tech Coloproctol. 2020;24:265-274.

14. Tozer P, Sala S, Cianci V, Kalmar K, Atkin GK, Rahbour $\mathrm{G}$, et al. Fistulotomy in the tertiary setting can achieve high rates of fistula cure with an acceptable risk of deterioration in continence. J Gastrointest Surg. 2013;17:1960-1965.

15. Ratto C, Litta F, Parello A, Zaccone G, Donisi L, De Simone V. Fistulotomy with end-to-end primary sphincteroplasty for anal fistula: results from a prospective study. Dis Colon Rectum. 2013;56:226-233.

16. Arroyo A, Pérez-Legaz J, Moya P, Armañanzas L, Lacueva $\mathrm{J}$, Pérez-Vicente F, et al. Fistulotomy and sphincter reconstruction in the treatment of complex fistula-in-ano: long-term clinical and manometric results. Ann Surg. 2012;255:935-939.

17. Göttgens KW, Janssen PT, Heemskerk J, van Dielen FM, Konsten JL, Lettinga T, et al. Long-term outcome of low 
perianal fistulas treated by fistulotomy: a multicenter study. Int J Colorectal Dis. 2015;30:213-219.

18. Sheikh P, Baakza A. Management of Fistula-in-Ano-The Current Evidence. Indian J Surg. 2014;76:482-486.

19. Kanchwala Q, Jain D, Phalgune D. Recurrence rates and fecal incontinence after fistulotomy or fistulectomy. Indian J Colo-Rectal Surg. 2018;1:43-47.
20. Bokhari S, Lindsey I. Incontinence following sphincter division for treatment of anal fistula. Colorectal Dis. 2010;12(7 Online):e135-e139.

21. Mei Z, Wang Q, Zhang Y, Liu P, Ge M, Du P, et al. Risk Factors for Recurrence after anal fistula surgery: A metaanalysis. Int J Surg. 2019;69:153-164.

22. Abraham Jebakumar, S. Shanmugam, Anbarasan. A comprehensive study of fistula in ano. IAIM, 2016;3:66-72. 